\title{
Effective heave pressures beneath restrained basement slabs
}

Brian Simpson OBE, MA, PhD, FICE, FREng

Arup Fellow, Arup, London, UK (brian.simpson@arup.com)

In basement excavations it is common practice to employ ground-bearing slabs that are restrained from significant vertical movement by piles or surrounding retaining walls. For the structural design of these slabs, it is necessary to assess the upward pressure, known as heave pressure, from the ground beneath the slab that will develop in the long term. This paper examines two different processes in current use for the calculation of long-term heave pressures beneath basement slabs, concluding that one of them is fundamentally flawed. For a very simple situation, it is shown that the final effective heave pressure is largely independent of the magnitude of ground stiffness, but is significantly dependent on other properties of ground behaviour. Estimation of long-term heave pressures is very difficult and field observations of long-term heave pressures and groundwater pressures at the time slabs are constructed are very much needed.

\section{Notation}

$c^{\prime} \quad$ effective cohesion

$D \quad$ depth of excavation

$E^{\prime} \quad$ Young's modulus for effective stresses in drained or undrained deformation

$E_{\mathrm{d}} \quad$ Young's modulus for drained deformation

$E_{\mathrm{u}} \quad$ Young's modulus for undrained deformation (total stresses)

$h_{1} \quad$ heave displacement due to undrained (constant volume) excavation

$h_{2} \quad$ heave displacement due to swelling and loss of suction before the slab is cast

$h_{3} \quad$ heave displacement due to long-term deformation of the slab caused by water pressure

$R \quad$ radius of circular excavation

$u \quad$ groundwater pressure

$u_{0} \quad$ initial water pressure

$\phi^{\prime} \quad$ effective angle of shearing resistance

$\gamma \quad$ total weight density of excavated ground

$\gamma_{\mathrm{w}} \quad$ weight density of water

$v^{\prime} \quad$ Poisson's ratio for effective stresses in drained or undrained deformation

$v_{\mathrm{d}} \quad$ Poisson's ratio for drained deformation

$v_{\mathrm{u}} \quad$ Poisson's ratio for undrained deformation (total stresses)

total stress

effective stress

vertical stress

vertical effective stress

initial vertical total stress

initial vertical effective stress

\section{Introduction}

Basement excavations commonly employ ground-bearing slabs that are restrained from significant vertical movement by piles or surrounding retaining walls. In the structural design of such slabs, it is necessary to assess the upward pressure from the ground beneath the slab that will develop in the long term. This pressure consists of long-term water pressure and vertical effective stress, termed the effective heave pressure (EHP). The term 'heave' itself will be taken here to mean upwards displacement. This paper concentrates on clay soils in which EHPs develop gradually after the slab has been cast and restrained.

A very simple example of the situation considered is shown schematically in Figure 1, representing a circular excavation in this case. It is assumed that the excavation is formed first and then the concrete slab is cast onto the excavated surface, with no provision for drainage. When the excavation is formed, water pressure in the soil beneath it will reduce, probably going into suction, but the water pressure will recover to its initial value in the long term. Before the slab is cast, the total vertical stress at the excavated surface is zero, so the water pressure and effective stress are equal and opposite. However, their values are dependent on many variables, potentially including

- the stiffness and strength of the ground, including non-linear behaviour

- the width and depth of the excavation in relation to the depth of the deforming ground beneath it

- the permeability of the ground and the timing of excavation and restraint of the slab

- the ability of the clay to hold the suction that will develop at the excavated surface

- sources of water that could enable the clay to swell

- the stiffness of the slab and of its restraining elements such as piles or retaining walls

- the geometry of structural elements in the ground and their interaction with the ground beneath the slab.

In the long term, the water pressure will recover to its initial value and vertical effective stress will also act on the underside of the slab. These pressures cause the slab to deflect to an 


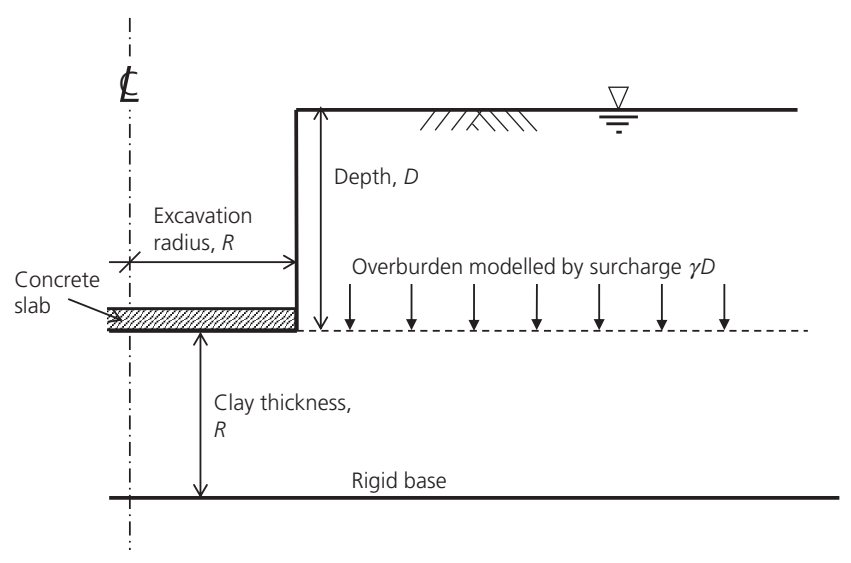

Figure 1. Excavation considered in this paper

extent dependent on its own stiffness and restraint, which might be provided by piles or the surrounding retaining walls. This paper is concerned with methods of trying to calculate the vertical effective stress acting beneath the slab in the long term, termed the long-term EHP. Although long-term heave pressure is important to the design of a slab, it is very difficult to measure, and no useful measurements are known to the author. For example, Price and Wardle (1986) monitored heave pressures beneath the raft slab of the Queen Elizabeth II Centre in London, but such results are specific to their context and are much affected by the loading and stiffness of the individual structure.

Several methods are available for calculation of long-term EHP, three of which are as follows.

(a) Assuming the long-term EHP to be a fixed proportion of the initial vertical effective stress that existed before the excavation was started. Given appropriate field data, this could be a useful empirical approach.

(b) Numerical analysis using a sequential finite-element (FE) program in which the excavation, casting and restraining of the slab, and long-term changes of stress are all modelled. In this paper, this is termed the 'FE process'.

(c) A simpler method, used to avoid the complications of FE analysis, which will be termed the 'non-FE process'. This has been used extensively in the industry and is considered by many engineers to be intuitively correct. It is described in Section 2.

The FE process provides a rigorous analysis and so is, in principle, correct as a process, although the values of many parameters that might affect the results may be difficult to determine.

The non-FE process (described in more detail later) is ideally intended to achieve the same results as the FE process, using simpler forms of calculation, often with approximations to model some of the complexities listed earlier. It will be shown, by means of a very simple example, that the non-FE process is fundamentally flawed and its results are meaningless in most cases. Regardless of any approximations involved in modelling the complexity of the real situation, the process itself is wrong. It will then be shown that the long-term EHPs are dependent on various properties of the ground, but not on the magnitude of stiffness.

\section{The non-FE process}

The non-FE process uses elastic theory to compute stress or displacement distributions, with either linear or non-linear assumptions for the stress-strain behaviour of the clay. The method uses the same forms of calculation as the approaches for calculating settlement and heave displacements described by O'Brien and Sharp (2001a, 2001b) and the 'stress-strain method' described in annex F of Eurocode 7 (BSI, 2013). Its application for calculation of heave pressures, the subject of this paper, is noted by Ellis and O'Brien (2012), but a detailed procedure is not provided. Calculations of this type can be carried out using computer programs such as Oasys PDisp (Oasys, 2015). This paper is concerned with the process in which such programs are used, not with the programs themselves.

In the non-FE process, two calculations are carried out separately rather than in sequence.

(a) The effect of excavation is modelled, assuming the clay to be undrained (constant volume), and the heave of the excavated surface is computed. The main driver of the displacement is the removal of the weight of excavation, which may be modelled by upwards tractions on the clay surface at the level of the excavation. The clay behaviour may be modelled by a range of constitutive models, although linear elasticity is often assumed at this stage. In some cases, additional components of heave may be added to this undrained calculation to allow for loss of suction and desaturation, or a certain amount of swelling of the clay if the excavation process is fairly slow.

(b) The calculation is repeated assuming the clay to be fully drained, to represent the long-term state. The behaviour of the clay is sometimes represented as linear elastic, or alternatively more complicated constitutive models may be adopted. In the latter case, a series of calculations is needed, imposing different heave pressures, to establish the relationship between drained heave and long-term EHP. If linear elastic behaviour is used, the stiffness may not necessarily be related to the undrained stiffness assumed in $(a)$ on the basis of a consistent elastic material; this provides a simple way of introducing the non-linear behaviour of the clay, modelling reduced stiffness during swelling.

(c) In separate calculations, the stiffness of the structural system (i.e. the slab and its restraints) is computed to relate upward displacement of the slab to the EHP and water pressure beneath it. 


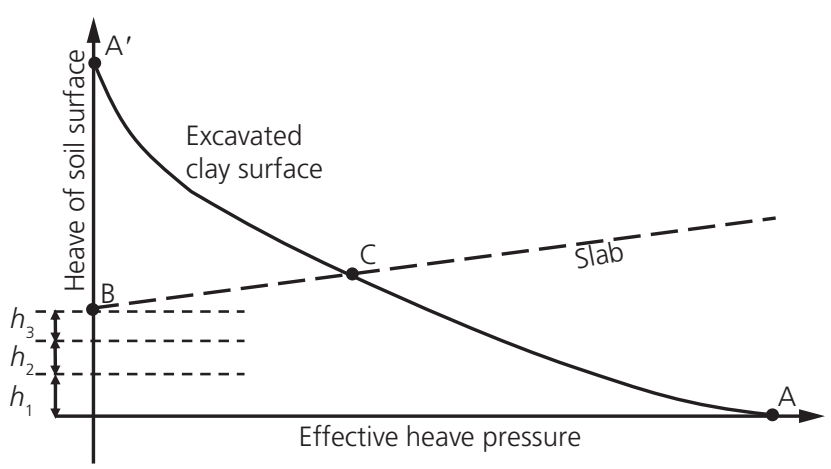

Figure 2. Schematic diagram of the 'non-FE' process

The results of these calculations can be represented as shown in Figure 2, in which the cumulative heave of the soil at the excavation surface is plotted against the long-term EHP. The solid and broken lines represent two ways of deriving this relationship, which can only both be correct at their intersection, point $\mathrm{C}$. The solid curved line $\mathrm{ACA}^{\prime}$ represents the heave of the excavated surface as a function of long-term EHP, as computed in (b) above. Point A represents the EHP that would be required to prevent any heave of the excavated surface; this would probably equal the initial vertical effective stress at the level of the excavated surface before excavation started. Point $\mathrm{A}^{\prime}$ represents unrestrained heave. Line $\mathrm{BC}$ represents the sum of the following four components.

- The heave of the soil surface that occurs during excavation due to undrained (constant volume) deformation of the ground $\left(h_{1}\right)$, as computed in $(a)$ above.

- Additional heave of the excavated surface that occurs before the slab is cast related to expansion of the soil due to swelling or loss of suction $\left(h_{2}\right)$.

- The long-term deflection of the slab due to water pressure $\left(h_{3}\right)$.

- The long-term deflection of the slab due to EHP, which gives the gradient of $\mathrm{BC}$, related to the stiffness of the slab and of its restraints.

In the non-FE process, it is then assumed that the intersection of the dashed line and the solid curve (point $C$ ) shows the final state, indicating the EHP acting on the slab. In practical situations, the response of the clay will not be the same at all points on the site as it will be affected by the proximity of piles and retaining walls, and possibly by excavations of differing levels. In that case, several versions of the figure will be needed, with differing curved lines $\mathrm{AA}^{\prime}$.

\section{Simplified case used for this study}

Figure 3 shows a simple case of the more general situations represented by Figure 2. This is the case that will be studied in this paper. By showing that the non-FE process yields the wrong result for a simple case, the process itself will be shown

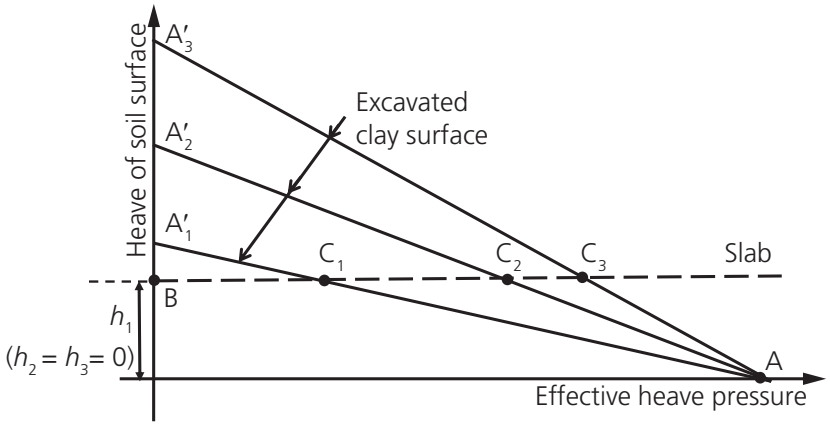

Figure 3. Simplified 'non-FE' process considered in this paper

to be fundamentally flawed. The following simplifications are adopted in Figure 3.

- The heave assumed before the slab is cast is taken to be only that due to undrained (constant volume) deformation of the clay $\left(h_{1}\right)$. No additions to this are included to allow for loss of suction and desaturation or swelling of the clay before the slab is cast and restrained (so $h_{2}=0$ ).

- The slab is assumed to be rigid and rigidly restrained, so once it has been cast and restrained it has no vertical displacement. As a result, component $h_{3}$ in Figure 2 is zero in Figure 3, and the broken line representing displacement of the slab due to EHP is horizontal in Figure 3.

- The behaviour of the clay is assumed to be linear elastic in both the undrained and drained phases, and its stiffness is assumed to be uniform and isotropic. As a result, the curve $\mathrm{AA}^{\prime}$ in Figure 2 becomes straight in Figure 3. In the undrained state, its elastic parameters are $E_{\mathrm{u}}$ and $v_{\mathrm{u}}$ and in the drained state $E_{\mathrm{d}}$ and $v_{\mathrm{d}}$, but it is not assumed that $E_{\mathrm{d}} / E_{\mathrm{u}}$ is necessarily equal to $\left(1+v_{\mathrm{d}}\right) /\left(1+v_{\mathrm{u}}\right)$, although this case will be included.

Three different values of drained stiffness are illustrated in Figure 3, giving three lines $\mathrm{AA}^{\prime}$ intersecting the slab line at $\mathrm{C}_{1}$, $\mathrm{C}_{2}$ and $\mathrm{C}_{3}$. That is, different drained stiffnesses result in different final EHPs. In this illustrative example, the undrained stiffness is the same for all three cases, so point B does not change.

\section{Analysis}

\subsection{Definition of the problem}

The type of problem represented by Figure 3 was analysed by both the FE process and the non-FE process described earlier. Both processes were reproduced in the FE program, Oasys Safe (Oasys, 2014). Figure 1 shows the problem considered, consisting of a circular excavation of radius $R$ and depth $D$, underlain by a layer of elastic 'clay', of thickness $R$ equal to the radius of the excavation, overlying a rigid base. The water table was taken to be at ground level, with hydrostatic pressures in the initial and final, long-term states. In the FE analyses, only the soil beneath the excavation was 
modelled, with the overburden above represented by surcharge; this replicates the normal procedure of the non-FE calculations. The restrained slab, shown cross-hatched, was not included in the model, but its effect was represented by restraining the nodes at the surface of the clay.

Oasys Safe models undrained behaviour by a consolidation analysis with very low permeability and a very short time period, which was used with elastic effective stress parameters $v^{\prime}$ and $E^{\prime}$. By this process, both effective stresses and pore water pressures are computed for the undrained phase in the idealised linear elastic 'clay'. For isotropic materials, this is equivalent to having a Poisson's ratio for total stresses $v_{\mathrm{u}}=0 \cdot 5$.

In the base case for the calculations, $E^{\prime}=10 \mathrm{MPa}$ and $v^{\prime}=0 \cdot 2$, giving $E_{\mathrm{d}}=E^{\prime}, v_{\mathrm{d}}=v^{\prime}$ and $E_{\mathrm{d}} / E_{\mathrm{u}}=0.8$. The values of other parameters adopted were $D=10 \mathrm{~m}, \gamma=20 \mathrm{kN} / \mathrm{m}^{3}$ and $\gamma_{\mathrm{w}}=10 \mathrm{kN} / \mathrm{m}^{3}$, so the initial vertical total and effective stresses at the excavation level were $\sigma_{\mathrm{v} 0}=200 \mathrm{kPa}$ and $\sigma_{\mathrm{v} 0}^{\prime}=100 \mathrm{kPa}$, respectively, and the initial water pressure was $u_{0}=100 \mathrm{kPa}$.

Table 1. FE runs representing the FE and non-FE processes

\begin{tabular}{|c|c|c|}
\hline Run & $E_{\mathrm{d}} / E_{\mathrm{u}}$ & Description \\
\hline U & & Undrained excavation \\
\hline Non-FE1 & $0 \cdot 8$ & Drained analysis carried out separately, \\
\hline Non-FE2 & 0.5 & independent of undrained excavation \\
\hline FE1 & $0 \cdot 8$ & Long-term drained state following undrained \\
\hline FE2 & 0.5 & excavation \\
\hline FE3 & $8 \times 10^{-6}$ & \\
\hline
\end{tabular}

The FE runs used to compare the FE and non-FE processes are listed in Table 1. For reference, all the material parameters used in the paper are recorded in Table 2. As will be apparent from the plotted results, a very coarse FE mesh was used for these analyses; the purpose was to demonstrate principles, not to produce accurate analyses of a real situation. The base of the mesh was fixed in both horizontal and vertical directions, whereas the centre-line and the remote boundary, at distance $10 R$, were allowed to slide vertically.

\subsection{Undrained stage}

For both the FE and the non-FE process, the first stage is to carry out the undrained analysis removing the overburden in the area of excavation (run U). Figure 4 shows the pore water pressures computed for this stage, indicating a water pressure of about $-60 \mathrm{kPa}$ (i.e. $60 \mathrm{kPa}$ suction) at the excavated surface. The water pressure had therefore reduced by $160 \mathrm{kPa}$ from its initial value, indicating a ratio $\bar{B}=\Delta u / \Delta \sigma_{\mathrm{v}}$ of about $0 \cdot 8$. This value is specific to this situation and is dependent on the geometry of the excavation and soil strata and on the distribution of stiffness, here assumed to be constant and isotropic. Dimensional analysis shows, however, that the computed water pressure, and hence the entire stress state, is not dependent on the magnitude of the ground stiffness $E_{\mathrm{u}}$, and this is readily confirmed by FE analysis. At the excavated surface, the vertical effective stress at this stage is $\sigma_{\mathrm{v}}^{\prime}=-u \approx 60 \mathrm{kPa}$.

\subsection{Non-FE process}

In the non-FE process, the second calculation is a drained analysis starting from the initial state before excavation and ending at the long-term state, with the final heave of the slab

Table 2. Material parameters used in the analyses

\begin{tabular}{|c|c|c|c|c|c|c|c|}
\hline \multirow[b]{2}{*}{ Run } & \multirow[b]{2}{*}{$E_{\mathrm{d}} / E_{\mathrm{u}}$} & \multicolumn{3}{|c|}{ Undrained stage } & \multicolumn{2}{|c|}{ Drained stage } & \multirow[b]{2}{*}{ Note } \\
\hline & & $E^{\prime}: \mathrm{MPa}$ & $v^{\prime}$ & $E_{\mathrm{u}}: \mathrm{MPa}$ & $E_{\mathrm{d}}=E^{\prime}: \mathrm{MPa}$ & $v^{\prime}$ & \\
\hline \multicolumn{8}{|c|}{ Runs with no horizontal restraint applied at the slab } \\
\hline $\begin{array}{l}\text { FE1 } \\
\text { Non- }\end{array}$ & $0 \cdot 8$ & 10 & $0 \cdot 2$ & $12 \cdot 5$ & 10 & $0 \cdot 2$ & \\
\hline $\begin{array}{l}\text { FE2 } \\
\text { Non-1 }\end{array}$ & 0.5 & As FE1 & & & $6 \cdot 25$ & $0 \cdot 2$ & \\
\hline FE3 & $8 \times 10^{-6}$ & As FE1 & & & 0.0001 & $0 \cdot 2$ & \\
\hline \multicolumn{8}{|c|}{ Runs with horizontal restraint at the slab } \\
\hline FE4 & $0 \cdot 8$ & As FE1 & & & & & \\
\hline FE5 & 0.8 & As FE1 & & & & & $c^{\prime}=0, \phi^{\prime}=25^{\circ}$ \\
\hline FE6 & $0 \cdot 8$ & As FE1 a & ation & hen gradient & & & $\mathrm{d} E^{\prime} / \mathrm{d} z=4 E_{0}^{\prime} / R$ \\
\hline FE7 & & $\begin{array}{l}E_{h}^{\prime}=20 \\
E_{v}^{\prime}=10\end{array}$ & $0 \cdot 2$ & $\begin{array}{l}\text { Derived } \\
\left(G_{\mathrm{vh}}=6 \cdot 25\right)\end{array}$ & $\begin{array}{l}E_{h}^{\prime}=20 \\
E_{v}^{\prime}=10\end{array}$ & $0 \cdot 2$ & \\
\hline FE8 & & As FE7 & & & & & Suction limit $30 \mathrm{kPa}$ \\
\hline FE9 & 0.87 & 10 & $0 \cdot 3$ & $11 \cdot 5$ & 10 & $0 \cdot 3$ & \\
\hline FE5a & $0 \cdot 8$ & As FE1 & & & & & $\begin{array}{l}c^{\prime}=0, \phi^{\prime}=25^{\circ} \text { in undrained } \\
\text { stage only }\end{array}$ \\
\hline FE5b & 0.8 & As FE2 & & & & & $c^{\prime}=0, \phi^{\prime}=25^{\circ}$ \\
\hline FE7a & & As FE7 & & & 10 & $0 \cdot 2$ & \\
\hline FE8a & & As FE7a & & & & & Suction limit $30 \mathrm{kPa}$ \\
\hline
\end{tabular}




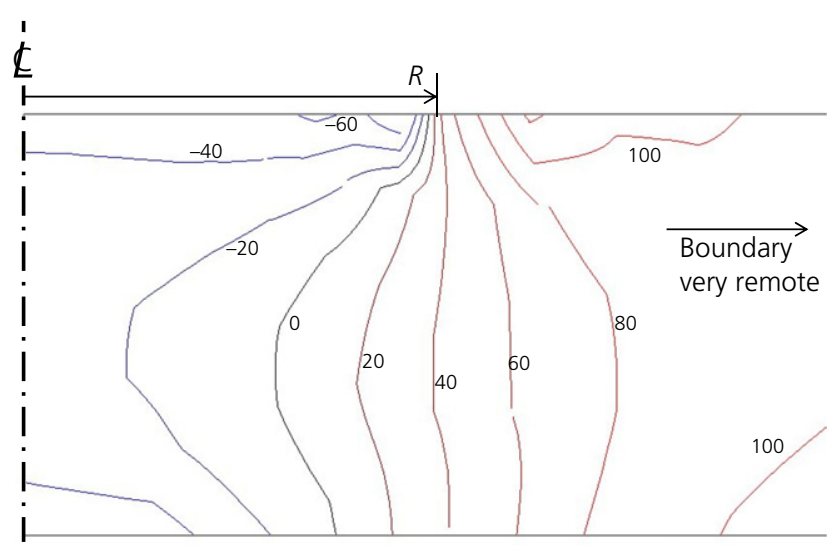

Figure 4. Computed water pressures (in $\mathrm{kPa}$ ) after undrained excavation

and final EHPs. Because it is assumed in this simple example that the slab is rigid and rigidly restrained, this can be achieved by imposing the vertical displacements derived from the undrained analysis on a separate drained analysis. No horizontal restraint is provided, however, since none is available when the process is carried out in the programs normally used for the non-FE process.

Table 1 shows two runs of this type (non-FE1 and non-FE2) carried out for different values of $E_{\mathrm{d}} / E_{\mathrm{u}}$, both of which might be used in practice. Figure 5 shows the computed final EHPs. These are different for the two values of $E_{\mathrm{d}} / E_{\mathrm{u}}$, as would be expected by comparison with Figure 3, with the lower value of $E_{\mathrm{d}}$ giving higher EHP (non-FE2).

\subsection{FE process}

In the FE process, the second stage, representing the long-term state after the slab has been cast and restrained, is carried out

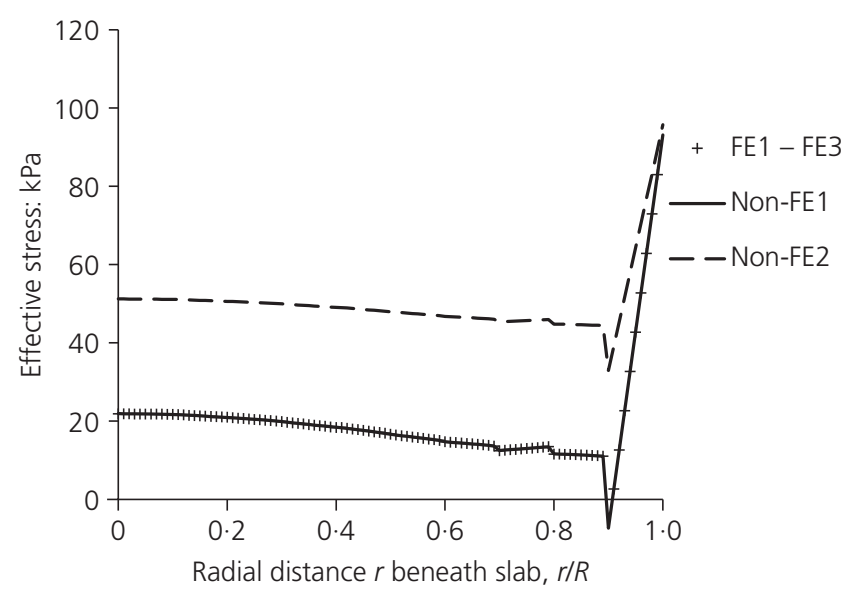

Figure 5. Computed final EHPs beneath restrained slab sequentially from the undrained stage. Since the slab was to be rigid, this was modelled by fixing the nodes vertically at the excavated surface in the positions they had reached in the undrained stage, changing the stiffness parameters to drained values and returning the water pressures to their initial hydrostatic values. In order to be consistent with the non-FE process, the nodes at the excavated surface were not restrained horizontally in this analysis.

Table 1 shows that run FE1 had the same value of $E_{\mathrm{d}} / E_{\mathrm{u}}$ as run non-FE1, in both cases representing a consistent elastic material throughout the analysis, with $E_{\mathrm{d}} / E_{\mathrm{u}}=$ $\left(1+v^{\prime}\right) /\left(1+v_{\mathrm{u}}\right)=0 \cdot 8$. Figure 5 shows that the computed longterm EHPs were the same for these two runs. This leads to conclusion 1: for a consistent elastic material, the non-FE process successfully reproduces the results of the FE process.

In run FE2 the FE process was repeated with the same parameters as run non-FE2; in run FE3 a very small value was used for the drained Young's modulus, $E_{\mathrm{d}} / E_{\mathrm{u}}=8 \times 10^{-6}$. It was found that the computed long-term EHPs were identical in these three runs using the FE process. Hence the second conclusion for this simple problem is: for the FE process, the longterm EHP is independent of the stiffness of the ground, $E_{\mathrm{d}}$, after the slab is cast and restrained.

This finding is directly contradictory to the assumption shown for the non-FE process in Figure 3 and verified in Figure 5. In these cases, the complete analysis does not represent a consistent elastic material for which $E_{\mathrm{d}} / E_{\mathrm{u}}=\left(1+v^{\prime}\right) /\left(1+v_{\mathrm{u}}\right)$. This leads to conclusion 3: if the undrained and drained stiffnesses are not those of a consistent elastic material, the non-FE process is not successful in reproducing the results of the FE process.

It was noted earlier that the computed stress state at the end of undrained excavation is independent of the undrained stiffness $E_{\mathrm{u}}$. As this stress state is the only driver for setting up the heave pressures, conclusion 3 can be extended to give conclusion 4: for the FE process, the long-term EHP is independent of both the undrained and drained stiffnesses $E_{\mathrm{u}}$ and $E_{\mathrm{d}}$.

Figure 6 shows the computed displacements during transfer from undrained to drained stages in run FE1. Although the stress states at the end of the three FE runs were the same, the computed displacements were very different, being inversely proportional in magnitude to the drained Young's modulus $E_{\mathrm{d}}$.

\subsection{Dimensional analysis}

The non-FE process represented by Figures 2 and 3 has been in use for many years and is thought to be intuitively correct. However, consideration from a dimensional point of view 


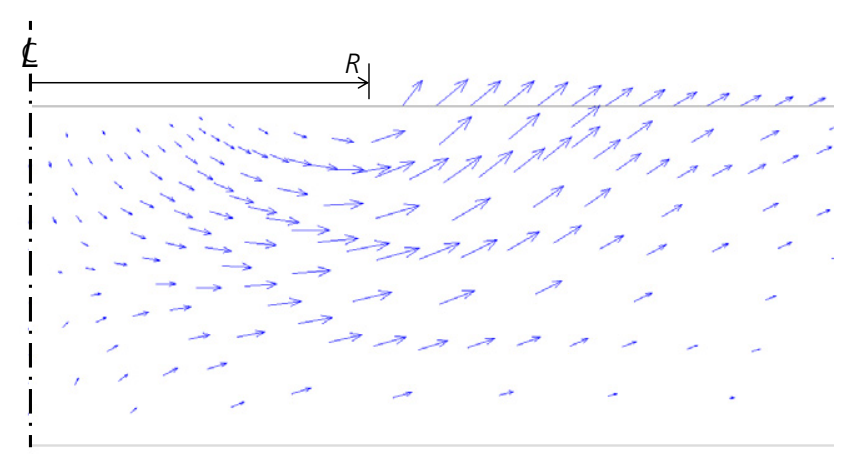

Figure 6. Computed displacements during transfer from undrained to drained stages (run FE1)

shows that this is not so. This is now considered for the simplified linear elastic case investigated in this paper.

For the undrained stage, the input, or 'action', is the digging of the excavation, represented here by a surface pressure, removal of $\gamma D$ (in units of $\mathrm{kPa}$ ). The resulting change of water pressure has the same units, so must be proportional to this. This means that the other parameter with the same units, undrained Young's modulus, cannot affect the resulting water pressures.

In the transfer from undrained to drained behaviour, the changes are caused only by the dissipation of water pressure (in units of $\mathrm{kPa}$ ), since there is no displacement of the slab. The resulting long-term EHP has the same units, so must be proportional to this. This means that the other parameter with the same units, the drained Young's modulus, cannot affect the resulting long-term EHPs.

This is contrary to the assumption of the non-FE process, revealing that it is fundamentally flawed.

If the slab were allowed to displace during the development of EHP, the heave pressure would be affected by another parameter, the displacement, which could form dimensionless groups with other geometric parameters and combine with the drained Young's modulus of the ground to affect the heave pressures.

\subsection{The problem with the non-FE process}

Since the non-FE process is generally considered by practitioners to be intuitively correct, it is relevant to identify where it is wrong. Implicitly, the method relies on the principle of superposition, which is often applied in elastic analyses and is defined in references such as Timoshenko and Goodier (1970). This states, in effect, that if a sequence of loads or imposed displacements is imposed on an elastic body, the order of the sequence has no effect and it is possible to consider its components separately and sum the results. In the present problem, the elastic body is the effective stress behaviour of the 'clay', represented by $E^{\prime}$ and $v^{\prime}$, this being the only elastic material in the analysis.

The principle of superposition only applies so long as the elastic body is unchanged throughout the analysis. This was the case in runs non-FE1 and FE1, so these gave the same result. However, in runs non-FE2 and FE2, the properties of the elastic body were changed part way through the analysis, since the effective stress stiffness in the drained stage was not equal to that in the undrained stage. Hence the two different processes gave different results. Since the FE process correctly represents the simplified problem posed here, it is clear that the non-FE process is flawed.

\section{Analyses for other soil models}

Comparisons will now be presented for a small range of soil behaviours, still using very simple models, and using the FE process. In all the analyses presented thus far, the clay was represented by a uniform linear elastic material and the slab provided vertical restraint, but no horizontal restraint. In the following analyses, the slab is assumed to provide rigid horizontal restraint once it is cast, besides vertical restraint.

\subsection{Consistent undrained and drained properties}

The materials listed in Table 3 were all used consistently in the undrained and drained stages in the FE process (i.e. the effective stress stiffness and strength properties were the same in both stages). Run FE4 was similar to run FE1 except that horizontal restraint was applied at the slab during the drained stage. FE5 is for an elastic Mohr-Coulomb material with limited strength; this was chosen as a very simple example of a non-linear model. Run FE6 is for a non-homogeneous elastic material, with stiffness increasing with depth, while FE7 is for a homogeneous anisotropic material. Run FE8 is for an anisotropic material and also has a limit on the suction that can be developed in the undrained stage, allowing some swelling and reduction of effective stress to occur before the slab provides restraint. FE9 is a uniform, isotropic linear elastic material but with Poisson's ratio $v^{\prime}=0 \cdot 3$ used consistently in the undrained and drained stages.

The vertical effective stresses at the excavated surface computed for all these runs at the end of undrained excavation are

Table 3. FE runs representing various soil models

\begin{tabular}{|c|c|c|}
\hline Run & $E_{\mathrm{d}} / E_{\mathrm{u}}$ & Variation \\
\hline FE4 & $0 \cdot 8$ & $\begin{array}{l}\text { Basic case, as FE1 but with horizontal restraint at } \\
\text { the slab in the drained stage }\end{array}$ \\
\hline FE5 & $0 \cdot 8$ & Elastic Mohr-Coulomb material with $c^{\prime}=0, \phi^{\prime}=25^{\circ}$ \\
\hline FE6 & $0 \cdot 8$ & Stiffness increasing with depth $z, \mathrm{~d} E^{\prime} / \mathrm{d} z=4 E_{0}^{\prime} / R$ \\
\hline FE7 & & Anisotropic effective stiffness. $E_{h}^{\prime}=2 E_{v}^{\prime}, v^{\prime}=0.2$ \\
\hline FE8 & & $\begin{array}{l}\text { As FE7, with suction limited to } 30 \mathrm{kPa} \text { in the } \\
\text { undrained case }\end{array}$ \\
\hline FE9 & 0.87 & As FE4, but with $v^{\prime}=0.3$ \\
\hline
\end{tabular}


shown in Figure 7; since total vertical stress is zero at this stage, water pressures would be equal and opposite to these, indicating suction. Different undrained water pressures and effective stresses were developed for the six different materials, contrasting with the finding for uniform linear elastic materials that these stresses were independent of the magnitude of stiffness. Figure 8 shows that, as a result of these differing undrained water pressures, the final drained vertical effective stresses beneath the slab also differed for these materials.

For the base case of a linear elastic material (FE4), the final EHP was less than $10 \mathrm{kPa}$, apart from a sharp rise close to the

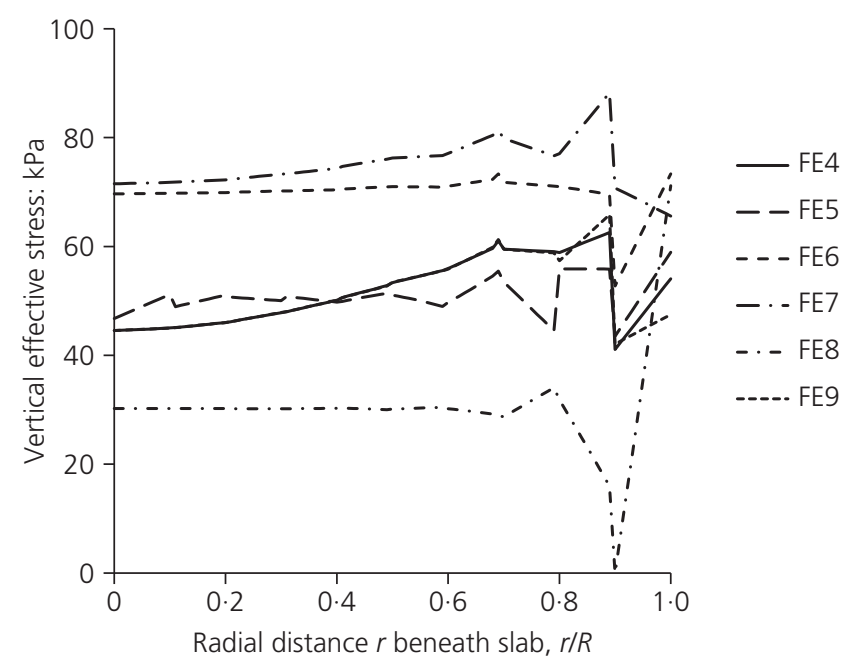

Figure 7. Computed vertical effective stress at the excavated surface following undrained excavation

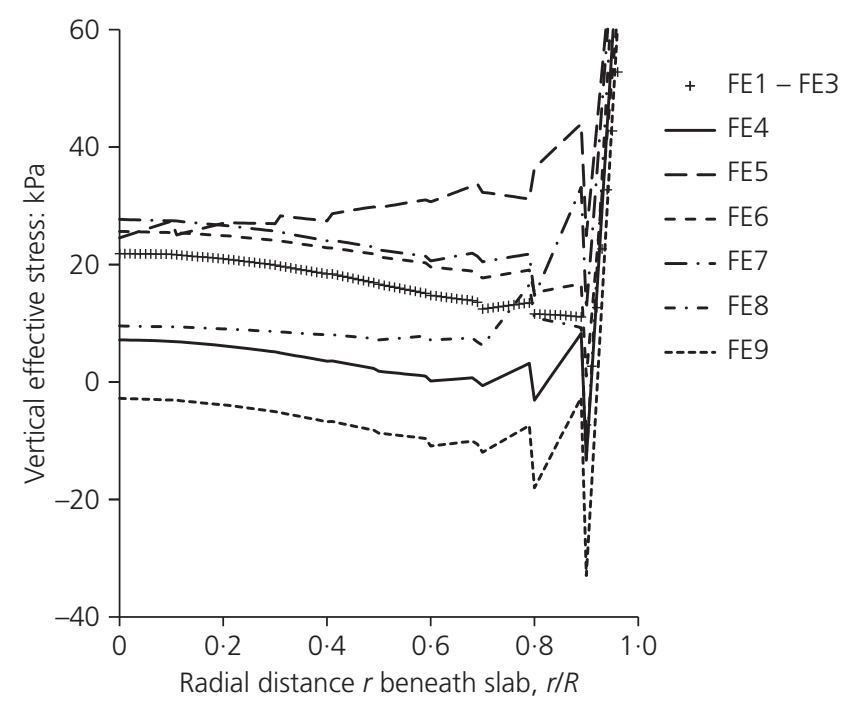

Figure 8. Computed final EHPs beneath slab - consistent materials edge of the slab. The results for runs FE1-FE3, in which the slab did not provide horizontal restraint, are also shown in Figure 8; apart from this horizontal restraint, run FE4 was identical to FE1. The results indicate that this restraint led to a significant reduction in the final EHP.

The highest final heave pressures were computed for run FE5 in which the strength of the soil was limited $\left(c^{\prime}=0, \phi^{\prime}=25^{\circ}\right)$. Increases in stiffness with depth (FE6) and anisotropy (FE7) both led to higher final EHPs than the uniform isotropic case (FE4). However, a comparison of runs FE7 and FE8 indicates that limiting the suction developed before the slab was restrained led to a reduction in final EHP. A change of Poisson's ratio from $0 \cdot 2$ (FE4) to $0 \cdot 3$ (FE9) also caused a reduction in the final EHP, in this case becoming negative for linear elastic material.

This leads to conclusion 5: although the undrained and drained magnitudes of elastic stiffness were found to have no effect on the final EHP in this problem, other features of the ground behaviour, including roughness of the slab/soil interface, strength limits, inhomogeneity, anisotropy, suction limits and Poisson's ratio, had significant effects.

\subsection{Inconsistent soil models}

It has been shown that, for homogeneous isotropic linear elastic materials, the undrained and drained stiffnesses and their ratios had no effect on the final EHP in the more correct FE process. That is, the undrained and drained materials could be 'inconsistent', with $E_{\mathrm{d}} / E_{\mathrm{u}} \neq\left(1+v^{\prime}\right) /\left(1+v_{\mathrm{u}}\right)$. Some further materials with inconsistency between the undrained and drained stages are now considered.

Table 4 shows some variants on runs FE5, FE7 and FE8, listed in Table 3 , in which the effective stiffness and strength parameters for the drained stages were changed from those of the undrained stages. Computed final EHPs are shown in Figure 9, in which the results for run FE5b overlay those of FE5.

For the case with limited strength (FE5), a change to linear elastic behaviour in the drained stage (FE5a) caused a

Table 4. FE runs with inconsistent undrained and drained materials

\begin{tabular}{|c|c|c|}
\hline Run & $E_{\mathrm{d}} / E_{\mathrm{u}}$ & Variation \\
\hline FE5a & 0.8 & $\begin{array}{l}c^{\prime}=0, \phi^{\prime}=25^{\circ} \text { for undrained stage, but linear } \\
\text { elastic for drained stage }\end{array}$ \\
\hline FE5b & 0.8 & $\begin{array}{l}c^{\prime}=0, \phi^{\prime}=25^{\circ} \text { for both stages. Isotropic undrained } \\
\text { and anisotropic } E_{h}^{\prime}=2 E_{v}^{\prime}, v^{\prime}=0 \cdot 2 \text { drained }\end{array}$ \\
\hline FE7a & & $\begin{array}{l}\text { Linear elastic, anisotropic as FE7 undrained, but } \\
\text { isotropic drained }\end{array}$ \\
\hline FE8a & & $\begin{array}{l}\text { As FE8, anisotropic with suction limit undrained, } \\
\text { but isotropic drained }\end{array}$ \\
\hline
\end{tabular}




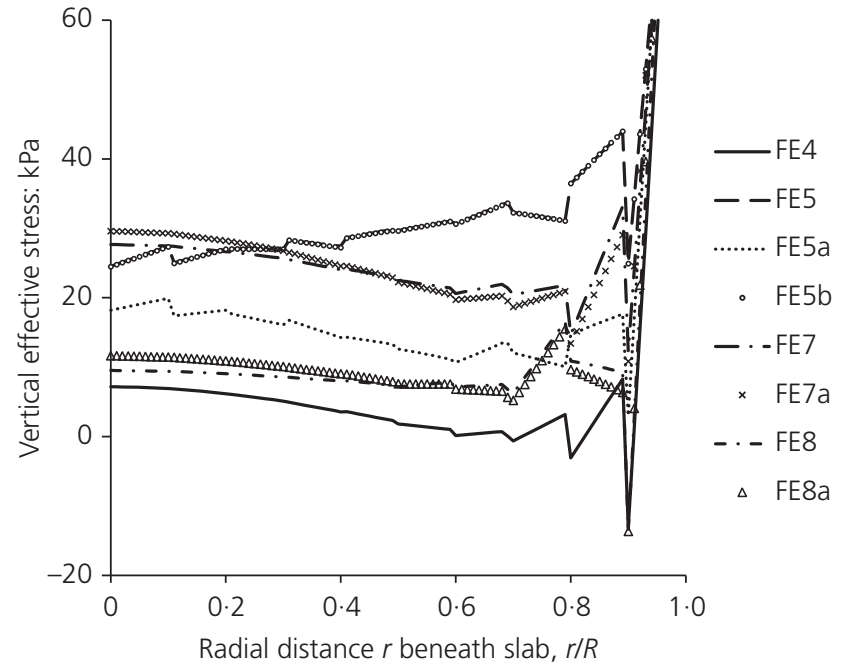

Figure 9. Computed vertical effective stress beneath slab inconsistent materials

significant reduction in final pressures. However, if the strength limit was retained but the material was made anisotropic in stiffness (FE5b), this has almost no effect. Runs FE7 and FE8 were both anisotropic in stiffness, whereas FE7a and FE8a were isotropic in the drained stages; this change had little effect.

Further analyses (not presented here) confirmed that if an inconsistent stiffness is used in the drained stage this generally has little effect; the final EHPs seem to be dependent on the water pressures set up in the undrained stage. However, a simple correlation between water pressure at the excavated surface when the slab becomes restrained and final EHP has not been established.

On the basis of this small sample of results, it appears that the strength of the soil in the drained stage is important, but changing the elastic properties at this stage may have only a small effect, as was found for the uniform linear elastic material.

\section{Discussion}

The conclusions drawn thus far were based on investigation of a highly simplified model of an excavation followed by construction of a completely restrained raft slab. Nevertheless, they are sufficient to demonstrate that the non-FE process fails to reproduce the rigorous results of the FE process. In particular, the concept shown in Figures 2 and 3, which implies that heave pressures are essentially dependent on the magnitude of stiffness of the ground, undrained and drained, is fundamentally flawed. Other features of the soil behaviour (including strength, anisotropy, inhomogeneity, suction limits and the properties of the interface with the slab) all have significant effects on the final EHP.
One aspect of the results that may give some comfort to designers using the non-FE process is that, provided the drained stiffness $E_{\mathrm{d}}$ was less than the effective stiffness $E^{\prime}$ used in the undrained phase, the computed final EHPs were found to be on the high side, giving a safe design in this example.

In the FE process, the only change that was imposed to effect the transfer from the undrained to the final drained situation was recovery of the water pressures. Hence it is these water pressures, existing at the time the slab becomes restrained, that actually govern the final EHPs. In a more realistic situation, water pressures are difficult to compute reliably, being dependent on many factors, including all the factors listed in Section 1 of this paper.

Advanced FE analyses that attempt to model all these factors should, in principle, be able to compute the final heave pressures, though this is difficult. The ability of the soil to hold suction is a particularly critical parameter, for which available data are generally scarce. Many stiff clays are fissured so, after excavation, the water pressure in the fissures and in intact blocks may be different, making measurements difficult: both probably contribute to the final heave pressure.

To get a better understanding of this problem, there is a clear need for field monitoring of final heave pressures. Even if further analytical calculations prove difficult, this could enable an empirical approach to design, relating the weight of the excavation to the final heave pressure in familiar ground conditions. Available measurements are rare.

High-quality measurements of water pressures (suction) at the time slabs become restrained would also provide very valuable input into FE or other computations of heave pressures. Such measurements are also not easy to obtain. One example was presented by Mettyear (1984), although the instruments used were limited by inability to measure suction.

If the slab is able to deflect appreciably as heave pressure increases, this aspect of structural stiffness will affect the final results and the stiffness of the swelling clay, in comparison with that of the restraining structure, will be relevant. An understanding of the stiffness in swelling might be obtained from laboratory tests on the clay or from observations of heave displacements at unrestrained clay surfaces. Such measurements of heave displacement, which are more readily available, could therefore be valuable, though in many cases involving heave pressures on slabs the deflection of the structure may be insufficient to influence final heave pressures significantly.

\section{Conclusions}

A simple study has been presented to compare alternative processes that could be used to predict long-term EHP beneath basement slabs restraining clay. For this study, the 'FE process' 
is able to provide correct results. The 'non-FE process' in current use in the industry has been shown to be fundamentally flawed. The following specific conclusions were drawn from the results of this study.

(a) For a consistent elastic material, the non-FE process successfully reproduces the results of the FE process. Here, 'consistent' means that $E_{\mathrm{d}} / E_{\mathrm{u}}=\left(1+v_{\mathrm{d}}\right) /\left(1+v_{\mathrm{u}}\right)$.

(b) For the FE process, the long-term EHP is independent of the stiffness $\left(E_{\mathrm{d}}\right)$ of the ground after the slab is cast and restrained.

(c) If the undrained and drained stiffnesses are not those of a consistent elastic material, the non-FE process is not successful in reproducing the results of the FE process.

(d) For the FE process, the long-term EHP is independent of both the undrained and drained stiffnesses $\left(E_{\mathrm{u}}\right.$ and $\left.E_{\mathrm{d}}\right)$.

(e) Although the undrained and drained magnitudes of elastic stiffness have been shown to have no effect on the final EHP in this problem, other features of ground behaviour have significant effects, including roughness of the slab-soil interface, strength limits, inhomogeneity, anisotropy, suction limits and Poisson's ratio.

Probably the most important driver for final EHPs is the water pressure (suction) in the ground at the time a slab becomes restrained. This is difficult to predict in real clay materials, which are non-linear in behaviour and often fissured. Field measurements of long-term heave pressures would therefore be very valuable. Field measurements of water pressures at the time slabs become restrained could also provide valuable insights and input to calculations of long-term heave pressures.
Observations of heave at unrestrained surfaces might also be valuable, especially for design in situations where slabs are able to deflect significantly as heave pressures develop.

\section{Acknowledgements}

The author gratefully acknowledges discussions about this subject with many colleagues in Arup.

\section{REFERENCES}

BSI (2013) BS EN 1997-1:2004 +A1:2013. Eurocode 7: Geotechnical design - Part 1: General rules. BSI, London, UK.

Ellis E and O'Brien AS (2012) Global ground movements and their effects on piles. In Chapter 57 of ICE Manual of Geotechnical Engineering (Burland J, Chapman T, Skinner H and Brown M (eds)). ICE Publishing, London, UK, pp. 887-898.

Mettyear NV (1984) The Short Term Behaviour of A Deep Cutting in London Clay. MSc dissertation, Imperial College, University of London, London, UK.

Oasys (2014) SAFE User Manual v19.1. Oasys Ltd, Newcastle upon Tyne, UK

Oasys (2015) PDisp User Manual v19.3. Oasys Ltd, Newcastle upon Tyne, UK.

O'Brien AS and Sharp P (2001a) Settlement and heave of overconsolidated clays - a simplified non-linear method of calculation, Part 1. Ground Engineering 34(10): 28-32.

O'Brien AS and Sharp P (2001b) Settlement and heave of overconsolidated clays - a simplified non-linear method of calculation, Part 2. Ground Engineering 34(11): 28-32.

Price G and Wardle IF (1986) Queen Elizabeth II Conference Centre: monitoring of load sharing between piles and raft. Proceedings of the Institution of Civil Engineers 80(6): 1505-1518, http://dx.doi.org/10.1680/iicep.1986.528.

Timoshenko S and Goodier JN (1970) Theory of Elasticity. McGraw-Hill, New York, NY, USA.

\section{How can you contribute?}

To discuss this paper, please email up to 500 words to the editor at journals@ice.org.uk. Your contribution will be forwarded to the author(s) for a reply and, if considered appropriate by the editorial board, it will be published as discussion in a future issue of the journal.

Proceedings journals rely entirely on contributions from the civil engineering profession (and allied disciplines). Information about how to submit your paper online is available at www.icevirtuallibrary.com/page/authors, where you will also find detailed author guidelines. 